\title{
Chapter 10 \\ Calcium Ion and Mineral Pathways in Biomineralization: A Perspective
}

\author{
Gal Mor Khalifa, Keren Kahil, Lia Addadi, and Steve Weiner
}

\begin{abstract}
Calcium transport from the environment to the final site of mineral deposition involves uptake from the water or the food into cells. Within the cells calcium ions are translocated to various organelles and vesicles where they accumulate, in such a way as to not raise the very low calcium concentrations in the cytosol. In various biomineralizing systems, the calcium is stored in vesicles as a highly disordered hence relatively soluble solid phase. The concentrated calcium phase is then translocated out of the cell to the site of mineralization. Additional pathways may involve transport through the vasculature as ions and possibly mineral from distant sites. Understanding calcium pathways is the foundation for not only better understanding biomineralization processes but also for better understanding calcium and its fundamental role in cell signaling.
\end{abstract}

Keywords Calcium uptake and transport - Seawater vacuoles $\cdot$ Calcium signaling - Mineral-containing vesicles

\subsection{Introduction}

One common attribute of all biologically mineralizing processes is that huge amounts of ions must be acquired from the environment, and transported to the site of mineralization, where they are deposited. In many mineralizing processes, the ions are temporarily stored in the form of highly unstable and disordered membranebound mineral phases inside the cells (Weiner and Addadi 2011). Furthermore, in many cases the mineral first deposited at the site of mineralized tissue formation is also an unstable disordered mineral ("precursor phase") that subsequently crystallizes into the mature phase (Beniash et al. 1997; Crane et al. 2006; Mahamid et al. 2010; Weiss et al. 2002).

G. M. Khalifa $\cdot$ K. Kahil $\cdot$ L. Addadi $\cdot$ S. Weiner $(\bowtie)$

Department of Structural Biology, Weizmann Institute of Science, Rehovot, Israel

e-mail: Gal.Mor@weizmann.ac.il; keren.kahil@weizmann.ac.il; lia.addadi@weizmann.ac.il;

steve.weiner@weizmann.ac.il 
Ion uptake and transport into cells and its temporary storage in cells are by no means confined to mineralization processes. In fact all cells need a suite of ions in order to function. Probably the best-studied ion in this respect is calcium. Calcium is used by all cells for signaling (Altin and Bygrave 1988; Carafoli 2005). For this to work, the cell needs to maintain a very low concentration of calcium in its cytosol - about 100-200 nM (Carafoli 2005), which is at least 10,000 times less concentrated than calcium in seawater (about $10 \mathrm{mmol}$ ) (Pietrobon et al. 1990). This signaling role of calcium requires the cell to take up calcium and store it in locations that do not contaminate the cytosol. This requirement must be even more stringent for cells that are involved in the calcium mineralization process, as they need to transport large amounts of calcium but also must have a functioning calcium signaling system.

Although a lot is known about the functions of calcium in cell metabolism, the actual distributions and concentrations of calcium ions in cells (not only in the cytosol) are not well documented. The main reasons for this are probably technical, as such mapping and measurements cannot be carried out on fixed and dehydrated specimens but require either in vivo measurements or a suitable fixation method. In vivo options for identifying ion concentrations are fluorescent probes which are sensitive to nanomolar concentrations (Rudolf et al. 2003) but not to the much higher concentrations that are relevant for the different stages in biomineralization. Identification of minerals in vivo is at present limited to micro-Raman spectroscopy, although the laser could conceivably induce amorphous minerals to crystallize. A most suitable fixation method for preserving ion concentrations and stabilizing unstable mineral phases is cryo-fixation. Cryo-fixation is the very rapid freezing of water such that ice crystals do not form, but the water is essentially frozen into a glassy or vitrified state. This method was developed by Dubochet (Dubochet et al. 1988). Mapping and measuring calcium concentrations in vivo or after cryo-fixation are, however, still technically very challenging. One promising option is cryo-soft X-ray tomography (Pereiro and Chichón 2014; Sviben et al. 2016).

\subsection{Calcium Uptake and Transport}

The ultimate source of ions is from the environment in which the organism lives. The ions can be extracted directly from the aqueous medium (seawater or freshwater) and/or from the food. Active ion-by-ion uptake takes place through ion-specific channels and pumps located in the cell membranes. Many proteins that bind one or several ions are known, and many are thought to be involved in ion transport (Pietrobon et al. 1990). These ion uptake and transport processes also occur in cells that are responsible for depositing mineral. Even if sufficient ions can be transported in these ways during rapid mineralization, or even during normal mineralization, are these the only pathways used? Much still remains to be learned about ion and mineral pathways in biology. 


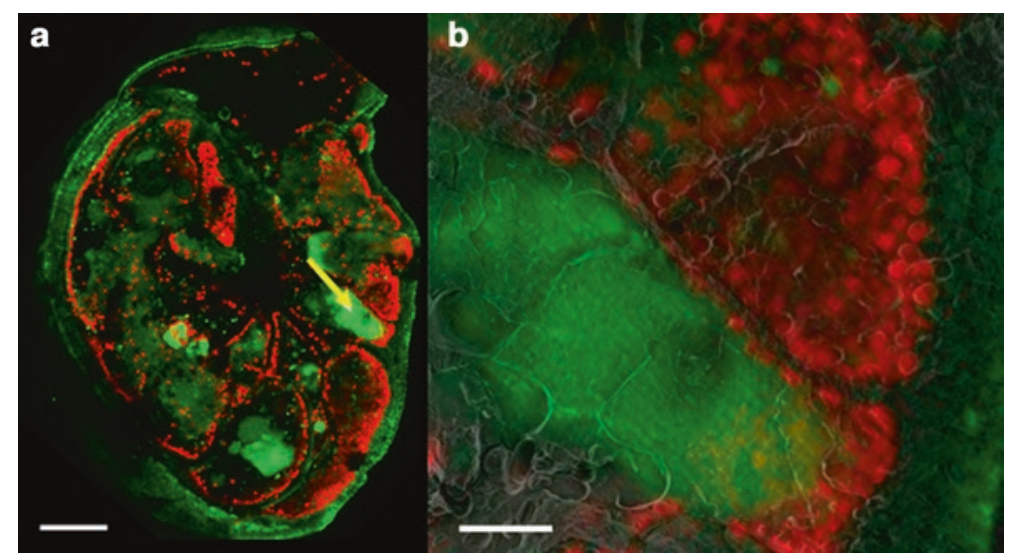

Fig. 10.1 Cryo-fluorescence images superimposed on a micrograph of high-pressure frozen and freeze-fractured Amphistegina lessonii. (a) A cryo-fluorescent image of a whole A. lessonii specimen superimposed on a freeze-fractured surface showing symbiont autofluorescence (red) and calcein labeling (green). The white arrow shows the location of one large seawater vacuole. Scale bar $=100 \mu \mathrm{m}$. (b) Magnified correlative cryo-SEM- fluorescence image of the seawater vacuole identified in image a. Scale bar $=20 \mu \mathrm{m}$

One approach is to use fluorescent molecules that are not able to pass through membranes: such as calcein and large fluorescently labeled polymers such as dextran (e.g., Butko et al. 1996). Organisms are grown in a medium in which one or both of these molecules are dissolved. If the fluorescent label enters the cell, then the marker molecules must have entered without passing through the membrane. One such process is endocytosis. As calcein is also a calcium-binding molecule, this is of particular relevance to tracking calcium in biomineralization. Bentov et al. (2009) monitored both these molecules in rapidly re-mineralizing benthic foraminifera whose shells had been previously dissolved so that the fluorescent signal could be imaged. These re-mineralizing foraminifera do indeed take up the fluorescent molecules, and these fluorescent molecules end up in the shell itself (Bentov et al. 2009). In this way Bentov et al. (2009) demonstrated that these organisms must be incorporating seawater droplets and at least some of the components of these droplets could be incorporated in the shell. Seawater droplet uptake was subsequently confirmed for intact foraminifera by imaging cryo-fixed fracture surfaces onto which fluorescent maps of the same cryo-fracture surface were superimposed (Khalifa et al. 2016). The calcein distribution in the foraminifer cytoplasm, investigated using this technique, shows that the foraminifer cell incorporates seawater droplets in a variety of sizes, starting from small micron-sized vesicles up to vacuoles tens of microns in size (Fig. 10.1). Seawater uptake was subsequently shown to occur in sea urchin larvae also using fluorescent dextran and calcein (Vidavsky et al. 2016). Surprisingly, the fluorescent markers labeled many sea urchin larval cells, in addition to the primary mesenchymal cells (PMCs) that are responsible for calcite spicule formation. Here the fluorescent calcein, but not the dextran, ends up in the calcitic spicule (Vidavsky et al. 2016). As seawater endocytosis is now known from 


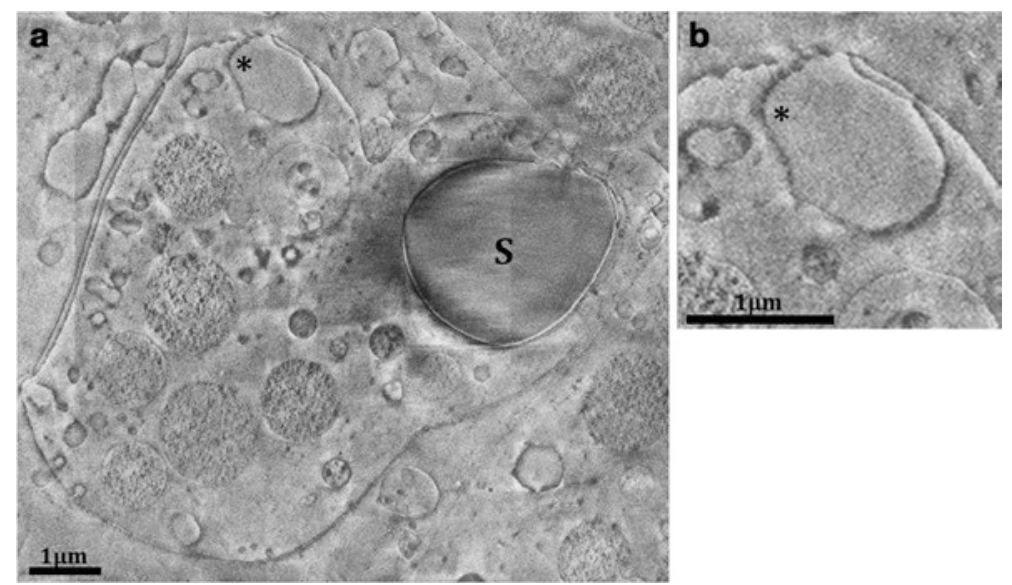

Fig. 10.2 Cryo-FIB-SEM micrograph of a single section of a high-pressure frozen sea urchin larva at the prism stage. (a) A primary mesenchyme cell attached to the spicule (S). A vesicle containing a uniform content similar in texture and gray levels to the cytoplasm and extracellular fluids is marked by an asterisk. This vesicle is close to the plasma membrane and has an opening to the extracellular fluids. (b) Higher magnification of the vesicle in a

two very different organisms, we suspect that the seawater occlusion uptake pathway may be widespread. This in turn opens up a fascinating question of how seawater can be manipulated chemically and/or biologically to enable specific ions, such as calcium, to be extracted without extracting all the other ions such as magnesium or strontium that are also present in seawater, in some cases in greater abundance than calcium.

In sea urchin larvae, seawater is incorporated into the body cavity (blastocoel). Many filopodia traverse the blastocoel, and it has been observed that the cells concentrate the calcein label into intracellular vesicles, and these vesicles move along the filopodia. They are transporting calcium in the form of a mineral, as shown by Raman spectroscopy, to the epithelial and mesenchymal cells (Vidavsky et al. 2015). Another possible mode of seawater uptake from the blastocoel was observed using cryo-FIB SEM to reconstruct the 3D organization of the constituents of the primary mesenchyme cells (PMCs) of sea urchin larvae - the cells responsible for calcite spicule formation. These cells contain vesicles, some of which have openings to the seawater-containing blastocoel (Fig. 10.2). In one case it was shown that such a vesicle is connected to other vesicles and/or vacuoles to form a large membranebound intracellular network (Vidavsky et al. 2016). It is conceivable, but not proven, that such a conduit might allow seawater with its calcium ions to move through the cell without contaminating the cytosol. Another option is to transport ions and/or minerals outside cells - either between cells as has been observed in coral epithelia responsible for skeletal mineralization (Gattuso et al. 1999) or as mineral-containing vesicles that have been observed in blood vessels of vertebrates (Kerschnitzki et al. 2016) and mollusks (Mount et al. 2004) and in the vertebrate extracellular matrix (so-called matrix vesicles) (Anderson 1995). 


\subsection{Temporary Calcium Storage in Cells}

Intracellular calcium is known to be stored in the sarcoplasmic reticulum, the endoplasmic reticulum, mitochondria, and various vesicles including the acidosomes (Docampo et al. 2005; García et al. 2006; Pezzati et al. 1997). Apparently what is not known is how the calcium is transported to these organelles or vesicles without contaminating the cytosol. It is also not known in which forms the calcium is stored at these locations. It is however known that in some sea urchin larval cells, calcium is stored in vesicles in the form of a highly disordered mineral phase, amorphous calcium carbonate (Beniash et al. 1999; Weiner and Addadi 2011). A particularly interesting mineral storage vesicle is present in Coccolithophoridae. This vesicle stores a calcium polyphosphate mineral (Sviben et al. 2016). This is surprising as Coccolithophoridae produce calcitic bodies (coccoliths). Intracellular mineral storage vesicles are also known in cells that are involved in bone formation (Akiva et al. 2015; Mahamid et al. 2011).

\subsection{Many Open Questions and Challenges Remain}

Many mineralization processes take place either in the extracellular environment or in relatively large vacuoles within the cell. The first formed mineral phase, however, is often found in membrane-bound vesicles within the cell (Weiner and Addadi 2011). Almost nothing is known about whether the temporarily stored calcium in the membrane-bound vesicles is transferred to the extracellular or intracellular sites of mineralized skeletal formation, and if so how is the calcium transferred out of the cell. In one case mineral-containing vesicles were observed to be exocytosed into the extracellular environment during bone formation (Boonrungsiman et al. 2012).

Foraminifera and sea urchin larvae are now known to take up ions by introducing seawater into the intracellular environment (Bentov et al. 2009; Vidavsky et al. 2016). This in turn raises the question of how this seawater is manipulated chemically and/or biologically to extract the calcium ions. One interesting observation is the presence of mineral bodies rich in magnesium in the seawater vesicles of foraminifera (Khalifa et al. 2016). How the Mg-rich mineral forms and for what purpose are as yet unanswered questions.

It was reported that the vasculature in developing chick bones contains membranebound mineral particles (Kerschnitzki et al. 2016). These vesicles must have formed at some other location and were introduced into the blood system. It is not known where these mineral particles form, but the implication is that bone formation involves many different cells, some of which may be located at considerable distances from the site of bone mineralization.

A 3D map of the distributions of ions in a cell would contribute significantly to our understanding of how all cells translocate and store large concentrations of ions without contaminating the cytosol. We still however do not have appropriate techniques to map the full range of ion concentrations in cells. 


\subsection{Concluding Comment}

Biologically mineralizing processes involve the uptake, transport, and deposition of large amounts of ions, often within a relatively short time. These systems are therefore advantageous for elucidating ion and mineral pathways in biology. Some of these pathways may be confined to mineralizing systems, but other pathways may also operate in all cells, as all cells require calcium and many other ions for performing basic functions. Thus elucidating these ion and mineral pathways in biomineralization may well contribute to our understanding of a fundamental biological process.

Acknowledgments LA and SW are the incumbents of the Dorothy and Patrick Gorman Professorial Chair of Biological Ultrastructure and the Dr. Trude Burchardt Professorial Chair of Structural Biology, respectively.

\section{References}

Akiva A, Malkinson G, Masic A, Kerschnitzki M, Bennet M, Fratzl P, Addadi L, Weiner S, Yaniv $\mathrm{K}$ (2015) On the pathway of mineral deposition in larval zebrafish caudal fin bone. Bone $75: 192-200$

Altin JG, Bygrave FL (1988) Second messengers and regulation of Ca2+ fluxes by $\mathrm{Ca} 2+-$ modulating agonists in rat liver. Biol Rev 63:551-611

Anderson HC (1995) Molecular biology of matrix vesicles. Clin Orthop 314:266-280

Beniash E, Aizenberg J, Addadi L, Weiner S (1997) Amorphous calcium carbonate transforms into calcite during sea-urchin larval spicule growth. Proc R Soc Lond B Ser 264:461-465

Beniash E, Addadi L, Weiner S (1999) Cellular control over spicule formation in sea urchin embryos: a structural approach. J Struct Biol 125:50-62

Bentov S, Brownlee C, Erez J (2009) The role of seawater endocytosis in the biomineralization process in calcareous foraminifera. Proc Natl Acad Sci U S A 106:21500-21504

Boonrungsiman S, Gentleman E, Carzaniga R, Evans ND, McComb DW, Porter AE, Stevens MM (2012) The role of intracellular calcium phosphate in osteoblast-mediated bone apatite formation. Proc Natl Acad Sci 109:14170-14175

Butko P, Huang F, Pusztai-Carey M, Surewicz WK (1996) Membrane permeabilization induced by cytolytic $\delta$-endotoxin CytA from Bacillus thuringiensis var. israelensis. Biochemistry $35: 11355-11360$

Carafoli E (2005) Calcium - a universal carrier of biological signals. FEBS J 272:1073-1089

Crane NJ, Popescu V, Morris MD, Steenhuis P, Ignelzi MA (2006) Raman spectroscopic evidence for octacalcium phosphate and other mineral species deposited during intramembraneous mineralization. Bone 39:431-433

Docampo R, de Souza W, Miranda K, Rohloff P, Moreno SNJ (2005) Acidocalcisomes - conserved from bacteria to man. Nat Rev 3:251-261

Dubochet J, Adrian M, Chang J-J, Homo J-C, Lepault J, McDowall AW, Schultz P (1988) Cryoelectron microscopy of vitrified specimens. Q Rev Biophys 21:129-228

García AG, García-De-Diego AM, Gandía L, Borges R, García-Sancho J (2006) Calcium signaling and exocytosis in adrenal chromaffin cells. Physiol Rev 86:1093-1131. https://doi. org/10.1152/physrev.00039.02005

Gattuso JP, Allemand D, Frankignoulle M (1999) Photosynthesis and calcification at cellular, organismal and community levels in coral reefs: a review on interactions and control by carbonate chemistry. Am Zool 39:160-183 
Kerschnitzki M, Akiva A, Ben Shoham A, Koifman N, Shimoni E, Rechav K, Arraf AA, Schultheiss TM, Talmon Y, Zelzer E, Weiner S, Addadi L (2016) Transport of membrane-bound mineral particles in blood vessels during chicken embryonic bone development. Bone 83:65-72

Khalifa MG, Kirchenbuechler D, Koifman N, Kleinerman O, Talmon Y, Elbaum M, Addadi L, Weiner S, Erez J (2016) Biomineralization pathways in a foraminifer revealed using a novel correlative cryo-fluorescence-SEM-EDS technique. J Struct Biol 196:155-163

Mahamid J, Aichmayer B, Shimoni E, Ziblat R, Li C, Siegel S, Paris O, Fratzl P, Weiner S, Addadi L (2010) Amorphous calcium phosphate transformation into crystalline mineral in zebrafish fin bones: mapping the mineral from the cell to the bone. Proc Natl Acad Sci U S A 107:6316-6321

Mahamid J, Sharir A, Gur D, Zelzer E, Addadi L, Weiner S (2011) Bone mineralization proceeds through intracellular calcium phosphate loaded vesicles: a cryo-electron microscopy study. J Struct Biol 174:527-535

Mount AS, Wheeler AP, Paradkar RP, Snider D (2004) Hemocyte-mediated shell mineralization in the Eastern oyster. Science 304:297-300

Pereiro E, Chichon FJ (2014) Cryo-soft X-ray tomography of the cell. eLS. Wiley, Chichester

Pezzati R, Bossi M, Podini P, Meldolesi J, Grohovaz F (1997) High-resolution calcium mapping of the endoplasmic reticulum-golgi-exocytic membrane system. Mol Biol Cell 8:1501-1512

Pietrobon D, Di Virgilio F, Pozzan T (1990) Structural and functional aspects of calcium homeostasis in eukaryotic cells. Eur J Biochem 193:599-622

Rudolf R, Mongillo M, Rizzuto R, Pozzan T (2003) Looking forward to seeing calcium. Nat Rev 4:579-586

Sviben S, Gal A, Hood MA, Bertinetti L, Politi Y, Bennet M, Krishnamoorthy P, Schertel A, Wirth R, Sorrentino A, Pereiro E, Faivre D, Scheffel A (2016) A vacuole-like compartment concentrates a disordered calcium phase in a key coccolithophorid alga. Nat Commun. https://doi. org/10.1038/ncomms 11228

Vidavsky N, Masic A, Schertel A, Weiner S, Addadi L (2015) Mineral-bearing vesicle transport in sea urchin embryos. J Struct Biol 192:358-365

Vidavsky N, Addadi S, Schertel A, ben-Ezra D, Shpigel M, Addadi L Weiner S (2016) Calcium transport into the cells of the sea urchin embryo: implications for spicule formation. Proc Natl Acad Sci U S A 113:12637-12642

Weiner S, Addadi L (2011) Crystallization pathways in biomineralization. Annu Rev Mater Res 41:21-40

Weiss IM, Tuross N, Addadi L, Weiner S (2002) Mollusk larval shell formation: amorphous calcium carbonate is a precursor for aragonite. J Exp Zool 293:478-491

Open Access This chapter is licensed under the terms of the Creative Commons Attribution 4.0 International License (http://creativecommons.org/licenses/by/4.0/), which permits use, sharing, adaptation, distribution and reproduction in any medium or format, as long as you give appropriate credit to the original author(s) and the source, provide a link to the Creative Commons license and indicate if changes were made.

The images or other third party material in this chapter are included in the chapter's Creative Commons license, unless indicated otherwise in a credit line to the material. If material is not included in the chapter's Creative Commons license and your intended use is not permitted by statutory regulation or exceeds the permitted use, you will need to obtain permission directly from the copyright holder.

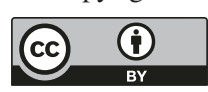

